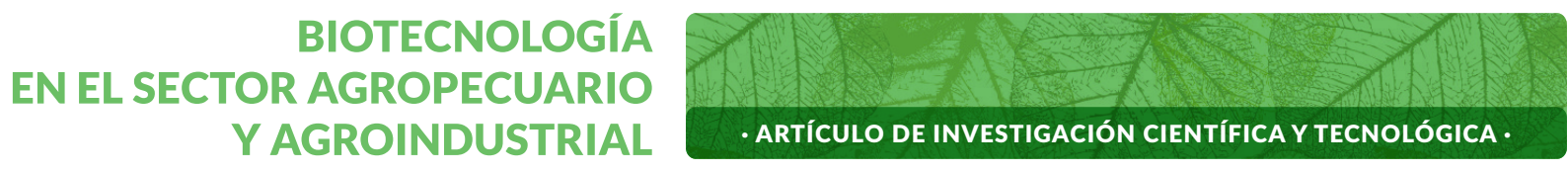

Vol. 18 No 2 · Julio - Diciembre 2020 • ISSN - 1692-3561 · ISSN-e 1909-9959 · DOI: http://dx.doi.org/10.18684

\title{
Efecto del suministro in vivo de Lactobacillus casei en la alimentación de Cavia porcellus*
}

\section{Efeito do suprimento in vivo de Lactobacillus casei na alimentação de Cavia porcellus}

\section{Effect of the in vivo supply of Lactobacillus casei in the feeding of Cavia porcellus}

\author{
HENRY JURADO-GÁMEZ", EDWARD ZAMBRANO-MORA², \\ CARLOS CHÁVEZ- VELÁSQUEZ ${ }^{2}$
}

Historial del Artículo

Recibido para evaluación: 21 de Junio 2019.

Aprobado para publicación: 4 de Mayo 2020.

* Proyecto de Investigación de origen: "Determinación in vivo del efecto probiótico de Lactobacillus casei microencapsulado mediante la técnica de spray drying, sobre morfología intestinal, respuesta inmunológica, parámetros bioquímicos y productivos del cuy". Financiación: Particular. Culminación: 2019.

1 Universidad de Nariño, Facultad de Ciencias Pecuarias, Departamento de Producción y Procesamiento Animal, Programa de Zootecnia, Grupo de Investigación PROBIOTECFORAPIS, Grupo de Investigación en Procesos Biotecnológicos Aplicados a la Producción Animal - Forrales y Apicultura. Ph.D en Ingeniería con Énfasis en Ingeniería de Alimentos. Pasto, Colombia. https://orcid.org/0000-0003-2118-7997

2 Universidad de Nariño, Facultad de Ciencias Pecuarias, Departamento de Salud Animal, Programa de Medicina Veterinaria, Grupo de Investigación PROBIOTEC-FORAPIS. M,Sc. Ciencias Agrarias. Pasto, Nariño. https://orcid.org/0000-0002-8443-2243 y https:// orcid.org/0000-0002-5815-4788.

Correspondencia: henryjugam@gmail.com

Cómo citar este artículo: HENRY JURADO-GÁMEZ, EDWARD ZAMBRANO-MORA, CARLOS CHÁVEZ- VELÁSQUEZ. Efecto del suministro in vivo de Lactobacillus casei en la alimentación de Cavia porcellus. Revista Biotecnología en el Sector Agropecuario y Agroindustrial,18(2),2020.156-165, DOI:http://dx.doi.org/10.18684/BSAA(18)156-165 


\section{RESUMEN}

El manejo sanitario de los sistemas de producción se realiza con la adición de antibióticos (APC) en el alimento; sin embargo, estas prácticas han incrementado los problemas de resistencia por parte de las bacterias patógenas. A partir de esto se evaluó el efecto del suministro de L. casei en los parámetros productivos y región gastrointestinal de esta especie. La investigación se realizó en las instalaciones y laboratorios de la Universidad de Nariño y se determinaron parámetros zootécnicos, cuadro hemático, química sanguínea y análisis coprológico. De igual manera, se realizó histología e inmunohistóquimica del intestino delgado de los animales. Se encontró que el suministro de la bacteria mostró parámetros productivos similares a los obtenidos con los tratamientos testigos. Los resultados para química sanguínea y orina presentaron variaciones en cuanto a los datos de referencia, sin embargo, se debe tener en cuenta que los animales utilizados para la evaluación presentan diferencia en cuanto al manejo, dado que la mayoría de reportes se tienen en animales de laboratorio y pocos en sistemas de producción. Además, se observó disminución en la presencia de lesiones gastrointestinales de los animales con suministro de L. casei. Los resultados demostraron la viabilidad del suministro de L. casei en cuyes.

\section{ABSTRACT}

The sanitary management of the production systems is carried out with the addition of antibiotics (GPA) in the food. However, these practices have increased resistance problems on the part of pathogenic bacteria. From this, the effect of the supply of $L$. casei on the productive parameters and gastrointestinal region of this species was evaluated. The research was carried out in the facilities and laboratories of the University of Nariño. Zootechnical parameters, blood count, blood chemistry and coprological analysis were determined. Similarly, histology and immune-histochemistry of the small intestine of the animals was performed. It was found that the bacterial supply showed productive parameters similar to those obtained with the control treatments. The results for blood and urine chemistry showed variations in reference data, however, it should be taken into account that the animals used for the evaluation have a difference in handling, given that the majority of reports are in animals of laboratory and few in production systems. In addition, there was a decrease in the presence of gastrointestinal lesions of animals with a supply of $L$. casei. The results demonstrated the viability of the supply of $L$. casei in guinea pigs.

\section{RESUMO}

O gerenciamento sanitário dos sistemas de produção é realizado com a adição de antibióticos (APC) nos alimentos; No entanto, essas práticas aumentaram os problemas de resistência por parte das bactérias patogênicas. A partir disso, foi avaliado o efeito do suprimento de L. casei nos parâmetros produtivos e na região gastrointestinal dessa espécie. A pesquisa foi realizada nas instalações e laboratórios da Universidade de Nariño. Parâmetros zootécnicos, hemograma, química sanguínea e análise coprológica foram determinados. Da mesma forma, foi realizada histologia e imuno-histoquímica do intestino delgado dos ani-

\section{PALABRAS CLAVE:}

Probiotico, Inocuidad alimentaria, Salud humana, Salud Animal.

\section{KEYWORDS:}

Probiotic, Food safety, Human

health, Animal health.

\section{PALAVRAS CHAVE:}

Probiótico, Segurança Alimentar, Saúde Humana, Saúde Animal. 
mais. Verificou-se que o suprimento bacteriano apresentou parâmetros produtivos semelhantes aos obtidos com os tratamentos controle. Os resultados para a química do sangue e da urina mostraram variações nos dados de referência, no entanto, deve-se levar em consideração que os animais utilizados para a avaliação apresentam diferenças no manuseio, uma vez que a maioria dos relatos é em animais de laboratório e poucos em sistemas de produção. Além disso, houve uma diminuição na presença de lesões gastrointestinais de animais com um suprimento de L. casei. Os resultados demonstraram a viabilidade do suprimento de L. casei em porquinhos-da-índia.

\section{INTRODUCCIÓN}

El uso indiscriminado de antibióticos promotores de crecimiento (APC) en los sistemas de producción animal ha incrementado la resistencia de bacterias patógenas intestinales, lo que provoca problemas sanitarios [1]. Las bacterias, como todos los seres vivos, tienen la capacidad de adaptarse a los cambios en el ambiente para mejorar su supervivencia. Junto a lo anterior, el ciclo biológico de las bacterias es corto, lo que eleva la probabilidad de presentar mutaciones que favorecen la resistencia [2]. Por otra parte, se ha observado que los microorganismos tienen la facultad de transmitir genes resistentes a otras especies bacterianas, lo que incrementa el problema [3].

Para evitar estas dificultades, las investigaciones se han enfocado en el uso de microorganismos que crean antagonismo con bacterias patógenas [4]. Dentro de este grupo, se encuentran las bacterias ácido lácticas (BAL), que se han estudiado de manera amplia en los seres humanos y algunas especies animales [5]. Al respecto, Lactobacillus casei ha mostrado efectividad en el control de bacterias patógenas y se ha descubierto que su antagonismo es producto de mecanismos como la disminución del pH del ambiente por la producción de ácido láctico, la producción de bacteriocinas, exclusión competitiva, y la estimulación del sistema inmune del huésped [4-6]. Todos estos mecanismos demuestran que $L$. casei es una bacteria con alto potencial para el manejo como microorganismo probiótico.

Sin embargo, el estudio de estos microrganismos en el cuy (Cavia porcellus) es escaso y falta mucho por comprender sobre la forma como interactúan con esta especie [7]. Al respecto, Aviles-Esquivel et al. [8] mencionan que el cuy es un animal herbívoro no rumiante, que se cría en la región andina de américa del sur como fuente de proteína. Se indica que el cuy se ha constituido en una especie productiva de alto rendimiento en los algunos países suramericanos, que ayuda a la seguridad alimentaria de zonas marginadas y con alto índice de pobreza [9].

De acuerdo a lo anterior, el objetivo de esta investigación fue determinar los efectos del suministro de L. casei en los parámetros productivos e histológicos del cuy (Cavia porcellus).

\section{MÉTODO}

Los experimentos fueron aprobados por el comité de ética de la Universidad de Nariño y los procedimientos se realizaron teniendo en cuenta las normas de bienestar animal de la República de Colombia.

Los análisis se realizaron en el laboratorio de investigación PROBIOTEC-FORAPIS, él área de cátedra y servicio de patología veterinaria de la clínica veterinaria Carlos Martínez Hoyos, el bioterio y laboratorios especializados de la Universidad de Nariño (Pasto, Colombia), situado entre los 2,500 y $2.800 \mathrm{msnm}$, tiene una precipitación de $980 \mathrm{~mm}$, temperatura de $13,1^{\circ} \mathrm{C}$ y humedad relativa promedias del $73 \%$, respectivamente. De igual manera, se utilizó el servicio de microscopia electrónica de la Universidad Nacional, Sede de Medellín (Colombia).

Se usó la cepa comercial Lactobacillus casei ATCC $\mathbb{R}$ 11456. Se ajustó el inóculo, y se realizaron pruebas de resistencia a $\mathrm{pH}$ de 7,5 y 9, siguiendo los procedimientos descritos por Jurado-Gámez et al.[10].

Para el ensayo in vivo se utilizaron 110 cuyes machos destetos (14 días de edad) de línea mejorada provenientes de una explotación particular tecnificada de cuyes del municipio de Tuquerres (Nariño, Colombia), con un peso promedio de $300 \pm 0,5 \mathrm{~g}$; los animales se distribuyeron en 4 tratamientos con 10 réplicas por tratamiento y 3 animales por réplica. Los tratamientos evaluados fueron: T1 alimento balanceado, forraje y agua destilada; T2 alimento balanceado, forraje y L. casei; T3 forraje y agua destilada; T4 forraje y L. casei. Los animales tuvieron un periodo de adaptación de cinco días, y el ensayo tuvo una duración de 40 días. El alimento balanceado no tuvo aditivos promotores de crecimiento y el agua destilada se usó como excipiente (placebo) en los tratamientos T1 y T4. 
El inóculo (L. casei) se suministró de forma oral mediante un gotero, a razón de $5 \mathrm{~mL} /$ animal/día distribuido en dos tomas (2,0 mL cada suministro), la primera a las 7:00 am y la segunda a las 5:00 pm. Se utilizó una concentración de $1 \times 10^{9} \mathrm{UFC} / \mathrm{mL}$ en el inóculo. Para la dieta con suplemento se suministró $310 \mathrm{~g}$ de forraje y $30 \mathrm{~g}$ de alimento balanceado, y para los tratamientos con solo forraje, este se incrementó 50 g para un total de 320 g día.

Al final de la investigación, los animales fueron sacrificados mediante la administración intravenosa de Pentobarbital sódico $(390 \mathrm{mg} / \mathrm{mL})$ y difenilhidantoína sódica $(50 \mathrm{mg} / \mathrm{mL}$ ) a una dosis de $1 \mathrm{~mL} / \mathrm{kg}$ peso. Se realizó evaluación macroscópica de los animales siguiendo la técnica de necropsia estandarizada por el laboratorio de patología de la Universidad de $\mathrm{Na}$ riño [11]. Se tomaron muestras del tracto gastrointestinal y se colocaron en formol buferado al $10 \%$ para fijación por 24 horas, luego se realizó el corte de duodeno, yeyuno e íleon y se ubicaron en cassettes para inclusión de tejidos debidamente rotulados; se les realizó inclusión en parafina y coloración de hematoxilina y eosina. Este procedimiento se realizó en las instalaciones de la fundación hospital San Pedro de Pasto (Colombia). De igual manera, se determinó el contenido de ácido láctico en la carne de cuy.

Se determinaron las variables productivas consumo de materia seca (CMS), ganancia de peso (GP) y conversión alimenticia (CA). De las muestras de sangre se determinó cuadro hemático, nitrógeno ureico (BUN) y creatinina, finalmente, se realizó análisis coprológico. La muestra de sangre fue obtenida por punción intracardiaca y las muestras de heces fueron tomadas directamente del colon al momento del sacrificio.

Los micropreparados de Hematoxilina y Eosina (H/E) de rutina se describieron y evaluaron histológicamente mediante visualización a través de microscopia óptica; para esto se tuvo como referencia histológica a Scundamure [12] y para la descripción de alteraciones microscópicas a Jubb et al. [13].

Las tinciones diferenciales fueron Tinción de Gram para identificación de bacterias Gram positivas y/o negativas; y ácido peryódico de Schiff (PAS) para detección de glucógeno y carbohidratos. Estas láminas se realizaron en la Corporación de patología veterinaria Corpavet ${ }^{\circledR}$ en la ciudad de Bogotá, Colombia.
Para precisar los hallazgos se emplearon marcadores monoclonales inmuno-histoquímicos de uso en humanos CD3 y CD79a a los bloques de parafina del tracto gastrointestinal de los animales para evaluar la expresión de linfocitos $T$ y $B$ del tejido linfoide asociado al intestino GALT.

Las muestras de los segmentos conservadas en glutaraldheido al $5 \%$ fueron analizadas en el Laboratorio de Microscopia electrónica de barrido de la Universidad Nacional, sede Medellín utilizando el protocolo para el procesamiento de este tipo de muestras definido por dicho Laboratorio.

La cepa láctica fue microencapsulada de acuerdo con lo descrito por Rodríguez et al. [14]; para ello, la bacteria se suspendió al 20\% p/v (60 g de Maltodextrina y $60 \mathrm{~g}$ de Inulina en $280 \mathrm{~mL}$ de Inóculo bacteriano previamente ajustado) en relación 1:1 p/p la cual se agitó hasta homogenizar.

Se utilizó el equipo de secado por aspersión Secador Spray Bilon $6000 \mathrm{~s} \AA$, con una temperatura de entrada de $170^{\circ} \mathrm{C}$ y una temperatura de salida en un rango de 65 a $67^{\circ} \mathrm{C}$ con ciclo completo de 2 horas y 30 minutos. El material microencapsulado se empaquetó en recipientes oscuros de plástico previamente esterilizados y se almacenaron a temperatura ambiente $\left(20 \pm 2^{\circ} \mathrm{C}\right)$.

Las pruebas de resistencia a diferentes $\mathrm{pH}$ se evaluaron mediante un diseño irrestrictamente al azar. Los parámetros productivos, la química sanguínea y el hematocrito fueron analizadas mediante análisis de varianza con el procedimiento PROC GLM del paquete estadístico SAS University [15]. El peso inicial se incluyó como covariable para consumo de materia seca. La comparación de medias se realizó con el procedimiento LSMEANS a un nivel de significancia del $5 \%$.

Para la caracterización microscópica, histoquímica e inmunohistoquímica del tracto gastrointestinal se empleó estadística descriptiva y registro fotográfico del proceso.

\section{RESULTADOS}

Los resultados mostraron que la bacteria fue resistente a $\mathrm{pH}$ básico, con un mayor crecimiento a $\mathrm{pH} 9$ ( $p<0,05$; figura 1). 
El suministro de agua destilada y el inóculo no mostraron problemas al momento de suministrarlos. Los resultados para consumo, ganancia de peso y conversión alimenticia se pueden observar en el cuadro 1.

Los valores indican que no hay diferencias en el CMS $(p>0,05)$. La ganancia de peso fue menor para los tratamientos T3 y T4 ( $p<0,05)$, mientras que la conversión alimenticia fue mas alta para el tratamiento T3 $(p<0,05)$.

Los resultados del hemograma se observan en el cuadro 2. No hubo diferencia para el contenido de hematocritos ( $p>0,05)$, mientras que los leucocitos y las proteínas totales fueron mayores en el T2 ( $p<$ $0,05)$; en cuanto a las plaquetas, se observa que T2 muestra el menor valor y los tratamientos T1 y T3 los valores más altos $(p<0,05)$; los neutrófilos fueron menores para el T3 y los linfocitos fueron menores en el T4 y mayores en el T3 $(p<0,05)$.

En el cuadro 2 se indican los resultados de BUN y creatinina. Se usaron como referencia los valores determinados por Washington y Van Hoosier [16]. El valor de creatinina fue diferente para el tratamiento T2 $(p<0,05)$, tratamiento que presentó valores inferiores a los de referencia; los otros valores no difirieron y se encuentran dentro del rango reportado. En cuanto a BUN, los valores encontrados fueron similares $(p>0,05)$, pero mayores a los de referencia.

Las características macroscópicas del coprológico mostraron valores normales para la especie con coloración marrón oscura, consistencia líquida, presencia de moco y no se observaron parásitos. Para las características microscópicas (cuadro 2), los resultados fueron positivos para la presencia de Isoporas en los tratamientos T1 y T2 y positivo en T3 para tropozoitos ciliados.

Figura 1. Resistencia a diferente $\mathrm{pH}$.

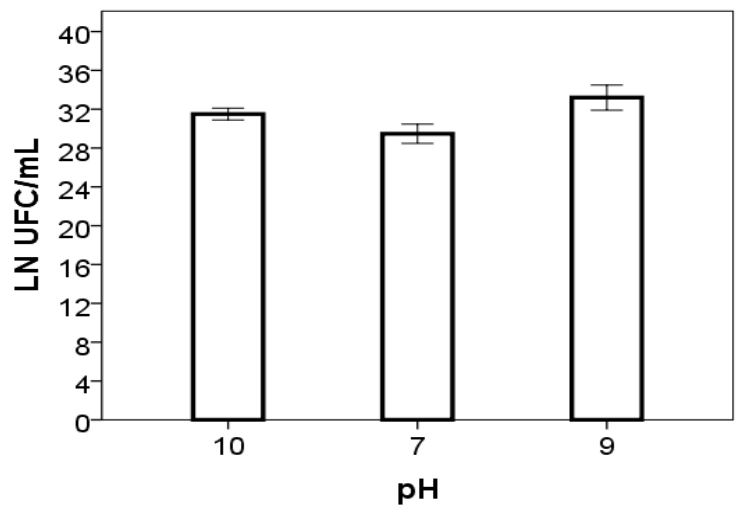

Cuadro 1. Valores de consumo de alimento, ganancia de peso y conversión alimenticia en cuyes.

\begin{tabular}{|l|c|c|c|c|}
\hline & T1 & T2 & T3 & T4 \\
\hline CMS & 1940,2 & 2011,03 & 2140,4 & 2148,5 \\
(g) & $\pm 23,10^{\mathrm{a}}$ & $\pm 24,09^{\mathrm{a}}$ & $\pm 22,99^{\mathrm{a}}$ & $\pm 32,5^{\mathrm{a}}$ \\
\hline GP & 397,6 & 402,4 & 273,0 & 311,1 \\
(g) & $\pm 20,3^{\mathrm{a}}$ & $\pm 10,4^{\mathrm{a}}$ & $\pm 15,2^{\mathrm{b}}$ & $\pm 13,2^{\mathrm{b}}$ \\
\hline CA & 4,9 & 5,01 & 6,95 & 6,13 \\
& $\pm 0,03^{\mathrm{b}}$ & $\pm 0,04^{\mathrm{b}}$ & $\pm 0,02^{\mathrm{a}}$ & $\pm 0,02^{\mathrm{ab}}$ \\
\hline
\end{tabular}

CMS: consumo de materia seca, GP: ganancia de peso, CA: conversión alimenticia.

Cuadro 2. Hematocrito y Parámetros bioquímicos en el cuy.

\begin{tabular}{|c|c|c|c|c|c|}
\hline Analito & REF. & T1 & T2 & T3 & T4 \\
\hline Hematocrito \% & $35-45$ & $47,5 \pm 1,23^{a}$ & $51 \pm 1,34^{a}$ & $47,5 \pm 1,07^{a}$ & $55,5 \pm 2,34$ \\
\hline Leucocitos $\times 10^{3} / \mu \mathrm{L}$ & $7-14$ & $3,1 \pm 0,45^{b}$ & $11 \pm 1,23^{a}$ & $3,15 \pm 0,56^{b}$ & $2,1 \pm 0,78^{b}$ \\
\hline Plaquetas $\times 10^{6} / \mu \mathrm{L}$ & $250-850$ & $410 \pm 16^{a}$ & $103 \pm 19 c$ & $441 \pm 25^{a}$ & $309 \pm 72^{b}$ \\
\hline Proteínas totales $\mathrm{g} / \mathrm{dL}^{1}$ & $4,6-6,2$ & $5,2 \pm 0,45^{b}$ & $6,4 \pm 0,35^{a}$ & $5,4 \pm 0,61^{b}$ & $5,5 \pm 0,34^{b}$ \\
\hline Neutrófilos seg. \% & $20-60$ & $30 \pm 1,23^{a}$ & $29 \pm 2,03^{a}$ & $17,3 \pm 1,56^{c}$ & $32 \pm 1,38^{a}$ \\
\hline Linfocitos \% & $30-80$ & $65 \pm 2,34^{b}$ & $67 \pm 3,02^{b}$ & $79,5 \pm 3,17^{a}$ & $59,5 \pm 3,22$ \\
\hline Monocitos \% & $2-20$ & $0,1 \pm 0,01^{b}$ & $1,0 \pm 0,19^{b}$ & $0,2 \pm 0,01^{b}$ & $0,4 \pm 0,01^{b}$ \\
\hline Eosinofilos \% & $0-5$ & 0 & 0 & 0 & 0 \\
\hline Basófilos \% & $0-1$ & 0 & 0 & 0 & 0 \\
\hline Absoluto (linfocitos) & $3000-8000$ & $2245^{b}$ & $8260^{a}$ & $2590^{\mathrm{b}}$ & $1310^{b}$ \\
\hline Creatinina (mg/dL) & $0,6-2,2$ & $0,7 \pm 0,01^{a}$ & $0,1 \pm 0,01^{b}$ & $0,5 \pm 0,01^{b}$ & $0,5 \pm 0,01^{b}$ \\
\hline BUN & $9-32$ & $32,9^{a}$ & $51,9^{a}$ & $39,2^{a}$ & $35,7^{a}$ \\
\hline Trichomonadida & -- & $\mathrm{N}$ & $\mathrm{N}$ & $\mathrm{N}$ & $\mathrm{N}$ \\
\hline Isospora spp & -- & $\mathrm{P}$ & $\mathrm{P}$ & $\mathrm{N}$ & $\mathrm{N}$ \\
\hline Balantidium coli & -- & $\mathrm{N}$ & $\mathrm{N}$ & $\mathrm{P}$ & $\mathrm{N}$ \\
\hline
\end{tabular}


Las placas teñidas no mostraron lesiones representativas en los tratamientos con L. caseí, pero si se observaron lesiones en los tratamientos control (figura 2).

En la Figura 3A se presenta los tejidos de duodeno. Esta tinción fue positiva para todos los tratamientos y su capa presentaba mayor grosor y fue más evidente que en los controles.

En la Figura 3B se indica la marcación para linfocitos $\mathrm{T}$ (CD3). Inicialmente la imagen (B1) corresponde al control y la (B2) al segmento íleon del tratamiento 4 con fuerte inmunomarcación.

En la figura $3 \mathrm{C}$ se observa la marcación de linfocitos $B$ (CD79). En la imagen (C1) del control positivo y la (C2) de duodeno, se aprecia fuerte inmunomarcación para linfocitos B. Se evidenció la presencia de ácido láctico en la carne de cuyes suplementados con cepas probióticas, con valores de 0,96 y $1,42 \mathrm{mg} / \mathrm{g}$ de carne; mientras que en los animales control no fue detectado.

\section{Otros hallazgos}

En la Figura 3E se presenta la morfología del parasito Balantidium coli, el cual fue observado durante el análisis de las láminas de Hematoxilina y Eosina sobre todo en el colon. Este parásito se identificó en los tratamientos 1 y 3 los cuales no recibieron LactobaciIlus casei. Los resultados de la microencapsulación se observa en la figura 3F, lo que indica que la bacteria fue microencapsulada de manera efectiva.

Los microorganismos candidatos a probiótico deben tener la capacidad de resistir los cambios en el pH del tracto gastrointestinal [17]. La zona del estómago presenta $\mathrm{pH}$ muy bajo, de alrededor de 3 , lo que imposibilita el crecimiento microbiano y se constituye en una barrera efectiva para invasores bacterianos [18]. Sin embargo, los análisis realizados en otros estudios in vitro han demostrado que $L$. casei tiene la capacidad de resistir estos $\mathrm{pH}$ tan bajos [10]. Al respecto, Subramanian et al. [19] manifiestan que las BAL disponen de mecanismos para regular la concentración de hidronios en el interior de la célula, que les permite disminuir su contenido y con ello evitar la acidez de su medio intracelular.

Dado que el estómago no es la única barrera en el tracto gastrointestinal, la porción del intestino delgado presenta valores de $\mathrm{pH}$ alcalinos, que alcanzan
Figura 2. Enteritis crónica moderada.

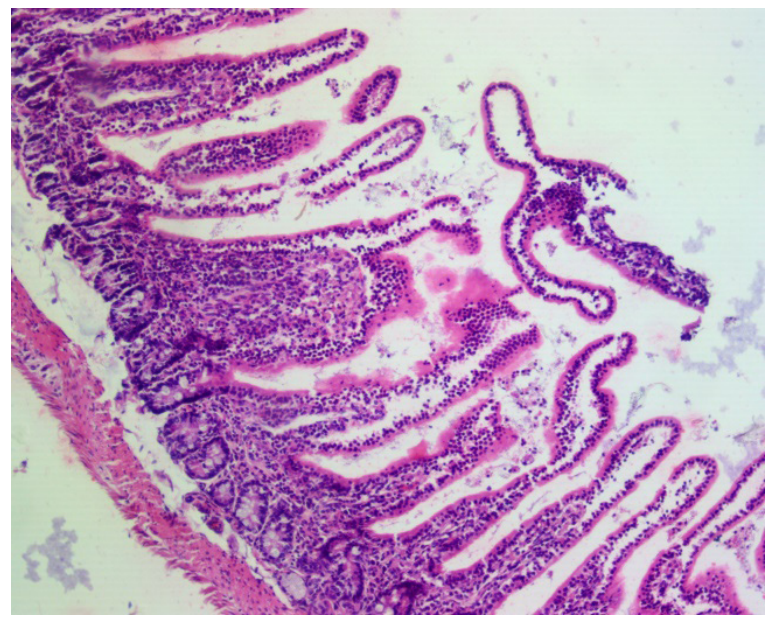

valores de 10; esto se convierte en un problema para la sobrevivencia de las bacterias probióticas [20]. La evaluación de diferentes $\mathrm{pH}$ alcalinos demostró buena viabilidad de $L$. casei a estas concentraciones. Al respecto, Aliaga et al. [21] indican que el intestino del cuy llega a presentar un valor de $\mathrm{pH}$ alrededor de 8 que es inferior a pH 10 evaluado en esta investigación, lo que posibilita la sobrevivencia de L. casei en esta zona, que le permitiría competir con otros organismos presentes en el tracto gastrointestinal del cuy [22]. Liu et al. [23] indican que un crecimiento de $1 \times 10^{\circ} \mathrm{UFC} / \mathrm{mL}(20,72$ Ln UFC/mL) es adecuado para colonizar el tracto gastrointestinal; al respecto, los valores encontrados en los distintos $\mathrm{pH}$ demuestran que la cepa tolera estas condiciones. Sin embargo, el crecimiento a pH 9 fue mayor, lo que indica que a estas condiciones, la cepa tiene mayores probabilidades de sobrevivencia.

En cuanto al consumo, Guevara y Carcelén [24] encontraron valores similares con el suministró de Lactobacillus y levadura. Por otra parte, Sáez-Lara et al. [25] indican que los probióticos no alteran la ingesta de los animales, corroborando los resultados encontrados. Aunque en otras especies, se ha observado una mejora en el consumo de los animales [26, 27], todavía no existe un consenso al respecto, por lo que falta mayor información para tener resultados concluyentes [28,30].

Los resultados para la ganancia de peso se deben al alimento balanceado, ya que los tratamientos T3 y T4 recibieron solo forraje. Al respecto, Caicedo et al. [9] mencionan que el cuy tiene un mayor rendimiento productivo cuando la dieta de forraje es enriquecida con el suministro de alimento balanceado, factor que 
Figura 3. Tinciones de inmunohistoquímica, Alcian Blue y diferenciadoras para el intestino delgado; microfotografías del tejido intestinal de Cavia porcellus; y microencapsulado de Lactobacillus caseí.

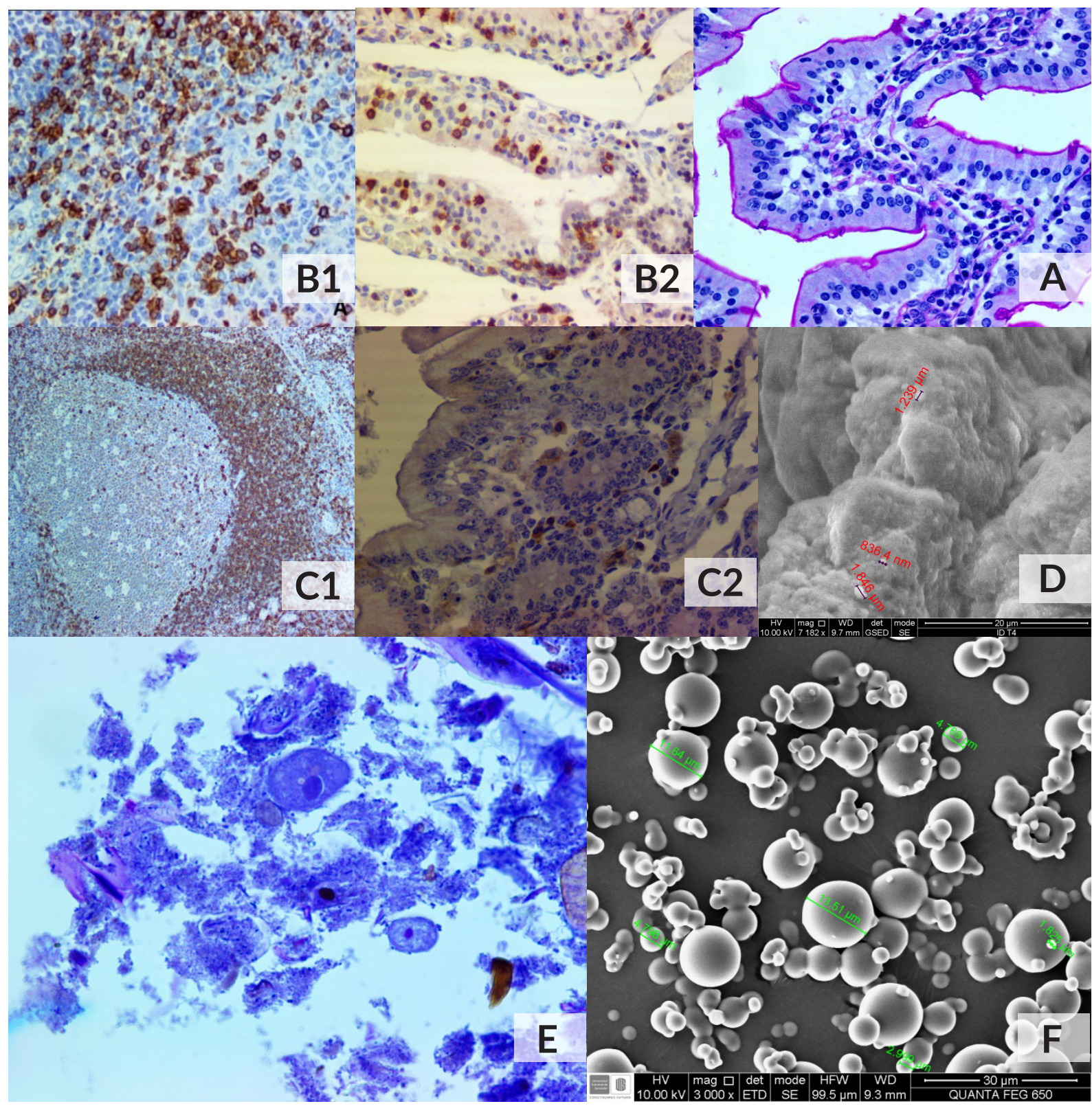

A: tinción de células caliciformes; B1: marcación linfocitos T (testigo); B2: marcación linfocitos T (ileon T4); C1: marcación linfocitos B (testigo); C2: marcación linfocitos B (duodeno T4); D: microencapsulación; E: parásito Balantidium coli (colon T1); F: tamaño y forma del microencapsulado.

explica las diferencias encontradas entre tratamientos. Sin embargo, todos los valores son similares a los reportados por Ramos et al. [31], lo que indica que no se alteró de manera significativa el parámetro bajo las condiciones evaluadas. Para la conversión alimenticia, los resultados son similares a la GP y se pueden explicar bajo el mismo fenómeno [32].
Los hallazgos histológicos muestran que L. casei se adhirió al tracto digestivo y muestra características de agente controlador de organismos patógenos. Los trabajos de Gamboa et al. [33] y Santarmaki et al. [34] mencionan que esta característica es muy importante para evaluar cepas bacterianas con fines probióticos. Entre los mecanismos antagónicos se ha observado 
que $L$. casei produce bacteriocinas que tienen diferentes formas de acción [35], algunas afectan directamente la membrana celular de otros microorganismo, otras inhiben procesos metabólicos vitales para la célula y, en la mayoría de los casos, las BAL pueden disminuir el $\mathrm{pH}$ del medio con la producción de ácido láctico [36]; todos estos mecanismos pueden regular el crecimiento de otros microorganismo y crear una barreras protectoras para el organismo huésped [37].

De igual manera, los hallazgos en el análisis coprológico mostraron una disminución de parásitos como consecuencia de la acción inhibitorio de L. casei. Sin embargo, falta conocer mucho sobre los mecanismos de acción con este tipo de parásitos, para identificar que realmente los efectos observados son consecuencia de los tratamientos evaluados [38].

La inmunomarcación observada puede ser una respuesta al daño tisular generado por las lesiones encontradas en los tejidos, un probable crecimiento bacteriano o una reacción con el medio de cultivo suministrado. Estos resultados indican que para el caso de los cuyes, el suministro de una dieta líquida alteró las condiciones gastrointestinales de los animales. Al respecto, los estudios realizados por Bustios et al. [39] revelan que en especies que tienen un bajo consumo de agua de bebida y que suplen sus requerimientos de este importante nutriente a través de los alimentos consumidos, pueden presentar alteraciones en el tracto digestivo como consecuencia del suministro de una sustancia (agua), cuando estos no se encuentran adaptados a este tipo de suministro.

\section{CONCLUSIONES}

El suministro de Lactobacillus casei en cuyes (Cavia porcellus) no afecta los parámetros productivos de consumo de alimento y ganancias de peso, pero si mejora la conversión alimenticia de los animales alimentados solo con forraje; lo anterior demuestra que el suministro de la bacteria láctica puede ser una alternativa al uso de antibióticos en los sistemas de producción. La inmuno histoquímica y la tinción Alcian Blue demostraron ser una herramienta útil para determinar lesiones en cuy. Sin embargo, se debe continuar con la evaluación de la cantidad de inóculo a suministrar.

\section{AGRADECIMIENTOS}

Los autores agradecen al grupo de investigación PROBIOTEC-FORAPIS del Departamento de Producción y Procesamiento Animal, Programa de Zootecnia de la Universidad de Nariño. Los resultados son el trabajo realizado por un estudiante de la Maestría en Ciencia Agrarias de la Universidad de Nariño.

\section{REFERENCIAS}

[1] MUND, M.D., KHAN, U.H., TAHIR, U., MUSTAFA, B.E. and FAYYAZ, A. Antimicrobial drug residues in poultry products and implications on public health: A review. International Journal of Food Properties, 20(7), 2017, p. 1433-1446. doi:https:// doi.org/10.1080/10942912.2016.1212874

[2] KOCH, B.J., HUNGATE, B.A. and PRICE, L.B. Food-animal production and the spread of antibiotic resistance: the role of ecology. Frontiers in Ecology and the Environment, 15(6), 2017, p. 309-318. https://doi.org/10.1002/fee.1505

[3] NKUKWANA, T.T. Global poultry production: Current impact and future outlook on the South African poultry industry. South African Journal of Animal Science, 48(5), 2018, p. 869-884. doi: 10.4314/sajas.v48i5.7

[4] ORTIZ-RIVERA, Y., SÁNCHEZ-VEGA, R., GUTIÉRREZ-MÉNDEZ, N., LEÓN-FÉLIX, J., ACOSTA-MUÑIZ, C. and SEPULVEDA, D.R. Production of reuterin in a fermented milk product by Lactobacillus reuteri: Inhibition of pathogens, spoilage microorganisms, and lactic acid bacteria. Journal of dairy science, $100(6), 2017$, p. 4258-4268. doi: 10.3168/jds.2016-11534.

[5] CAMPANA, R., VAN HEMERT, S. and BAFFONE, $W$. Strain-specific probiotic properties of lactic acid bacteria and their interference with human intestinal pathogensinvasion. Gut pathogens, 9(1), 2017, p. 12. doi: 10.1186/s13099-017-0162-4.

[6] LEMME-DUMIT, J.M., POLTI, M.A., PERDIGON, G. and GALDEANO, C.M. Probiotic bacteria cell walls stimulate the activity of the intestinal epithelial cells and macrophage functionality. Beneficial microbes, 9(1), 2018, p. 153-164. doi: 10.3920/ BM2016.0220.

[7] REN, X., ZHU, Y., GAMALLAT, Y., MA, S., CHIWALA, G., MEYIAH, A. and XIN, Y. E. coli O124 K72 alters the intestinal barrier and the tight junctions 
proteins of guinea pig intestine. Biomedicine \& Pharmacotherapy, 94, 2017, p. 468-473. doi: 10.1016/j.biopha.2017.07.123

[8] ÁVILES-ESQUIVEL, D., MARTÍNEZ, A., LANDI, V., ÁLVAREZ, L., STEMMER, A., GÓMEZ-URVIOLA, N. y DELGADO, J. Caracterización genética del cuy doméstico en América del Sur usando marcadores moleculares. Trópical and subtropical Agroecosystems, 21, 2018, p. 1-10.

[9] CAYCEDO-VALLEJO, A., ZAMORA-BURBANO, A., ECHEVERRY-POTOSI, S., ENRIQUEZ-CHAMORRO, R., ORTEGA-DAVID, E. y BURGOS-VELASCO, M. Producción de cuyes. 1 ed. Pasto (Colombia): Editorial Universidad de Nariño, 2011, 220 p.

[10] JURADO-GÁMEZ, H. and FAJARDO-ARGOTI, C. Determination of the probiotic in vitro effect of Lactobacillus gasseri on a Staphylococcus epidermidis strain. Biosalud, 16(2), 2017, p. 53-69. doi:http:// dx.doi.org/10.17151/biosa.2017.16.2.6

[11] ASTAIZA-MARTÍNEZ, J., BENAVIDES-MELO, J., CHAVES-VELÁSQUEZ, C., ARCINIEGAS-RIVERA, A. y QUIROZ-MORAN, C.L. Estandarización de la técnica de necropsia en cuyes (Cavia porcellus) en la Universidad de Nariño. Revista Investigación Pecuaria, 2(2), 2014, p. 79-83.

[13] JUBB, KENNEDY and PALMER. Pathology of Domestic Animals. 6 ed. Washington (USA): Elsevier, Inc. 2016, 670 p.

[14] RODRÍGUEZ-BARONA, S., GIRALDO, G. y MONTES, L. Encapsulación de alimentos probióticos mediante liofilización en presencia de prebióticos. Información tecnológica, 27(6), 2016, p. 135-144.

[15] CODY, R. An introduction to SAS university edition. 1 ed. Chicago (USA): SAS Institute, 2018, 880 p.

[16] WASHINGTON, M.I. and VAN-HOOSIER, G. Capítulo 3. Clinical Biochemistry and Hematology. En: The Laboratory Rabbit, Guinea Pig, Hamster and Other Rodents. 1 ed. Boston (USA): Academic Press, 2012, p. 94-96.

[17] WANG, C., CUI, Y. and QU, X. Mechanisms and improvement of acid resistance in lactic acid bacteria. Archives of microbiology, 200(2), 2018, p. 195-201. doi: 10.1007/s00203-017-1446-2.

[18] YASUTOMI, E., HOSHI, N., ADACHI, S., OTSUKA, T., KONG, L., KU, Y. and OOI, M. Proton pump inhibitors increase the susceptibility of mice to oral infection with enteropathogenic bacteria. Digestive diseases and sciences, 63(4), 2018, p. 881-889. doi: 10.1007/s10620-017-4905-3.
[19] SUBRAMANIAM, R., THIRUMAL, V., CHISTOSERDOV, A., BAJPAI, R., BADER, J. and POPOVIC, $M$. High-density cultivation in the production of microbial products. Chemical and biochemical engineering quarterly, 32(4), 2018, p. 451-464. doi:https://doi.org/10.15255/CABEQ.2018.1394

[20] CROWLEY, E.J., KING, J.M., WILKINSON, T., WORGAN, H.J., HUSON, K.M., ROSE, M.T. and MCEWAN, N.R. Comparison of the microbial population in rabbits and guinea pigs by next generation sequencing. PloS one, 12(2), 2017, p. e0165779. doi:https://doi.org/10.1371/journal.pone.0165779

[21] ALIAGA, L., MONCAYO, R., RICO, E. y CAYCEDO, A. Producción de cuyes. 1 ed. Lima (Perú): UCSS, 2009, 760 p.

[22] DOMINGOS, I., VELLANO, I.H., MORAES, A.C., ALTARUGIO, R., FILHO, A., OKAMOTO, A.S. and TRENTO, G.D. Measurement of in vitro Inhibition by Lactobacillus spp. against Salmonella Heidelberg. International Journal of Poultry Science, 17, 2018, p. 184-188. doi: 10.3923/ijps.2018.184.188

[23] LIU, C., ZHU, Q., CHANG, J., YIN, Q., SONG, A., LI, Z. and LU, F. Effects of Lactobacillus casei and Enterococcus faecalis on growth performance, immune function and gut microbiota of suckling piglets. Archives of animal nutrition, 71(2), 2017, p. 120-133. doi: 10.1080/1745039X.2017.1283824

[24] GUEVARA, J. y CARCELÉN, F. Efecto de la suplementación de probióticos sobre los parámetros productivos de cuyes. Revista Peruana de Química e Ingeniería Química, 17(2), 2014, p. 71. Doi:http:// dx.doi.org/10.15381/rivep.v30i2.16071

[25] SAES-LARA, M., ROBLES-SÁNCHEZ, C., RUÍZ-OJEDA, F., PLAZA-DÍAZ, J. and GIL, A. Effects of probiotics and synbiotics on obesity, insulin resistance syndrome, Type 2 diabetes and non-alcoholic fatty liver disease: A Review of human clinical trials. International Journal of Molecular Science, 17, 2016, p. 928. doi: 10.3390/ijms17060928.

[26] ADHIKARI, P.A. and KIM, W.K. Overview of prebiotics and probiotics: focus on performance, gut health and immunity-a review. Annals of animal science, 17(4), 2017, p. 949-966. doi:https://doi. org/10.1515/aoas-2016-0092

[27] YUAN, L., CHANG, J., YIN, Q., LU, M., DI, Y., WANG, P. and LU, F. Fermented soybean meal improves the growth performance, nutrient digestibility, and microbial flora in piglets. Animal Nutrition, 3(1), 2017, p. 19-24. doi:https://doi.org/10.1016/j. aninu.2016.11.003 
[28] MAHFUZ, S.U., NAHAR, M.J., MO, C., GANFU, Z., ZHONGJUN, L. and HUI, S. Inclusion of probiotic on chicken performance and immunity: A review. International Journal of Poultry Science, 16, 2017, p. 328-35. doi: 10.3923/ijps.2017.328.335

[29] DOWARAH, R., VERMA, A.K. and AGARWAL, $\mathrm{N}$. The use of Lactobacillus as an alternative of antibiotic growth promoters in pigs: a review. Animal Nutrition, 3(1), 2017, p. 1-6. doi:https:// doi.org/10.1016/j.aninu.2016.11.002

[30] CHEN, H.J., YANG, W.Y. and WANG, C.Y. The review on the function of intestinal flora and the regulatory effects of probiotics on the intestinal health of rabbits. Memorias 2nd International Conference on Biological Sciences and Technology (BST 2017). Atlantis (USA): University Atlantis, 2017 p. 34-42.

[31] RAMOS-OBANDO, L., GUEVARA-BURBANO, A.C. y VILLOTA-ARTEAGA, M.I. Evaluación de la producción de cuyes Cavia porcellus alimentados con pasto aubade Lolium sp. y forraje de abutilón Abutilon striatum. Revista investigación pecuaria, 2(1), 2015, p. 34-39.

[32] BALAGUER, C.M., CAPILLA, A.C., DELGADO, V.A. and MACÍAS, D.S. A comparison of the growth performance, carcass traits, and behavior of guinea pigs reared in wire cages and floor pens for meat production. Meat science, 152, 2019, p. 38-40. doi:https://doi.org/10.1016/j.meatsci.2019.02.012

[33] GAMBOA, R.G., BASURTO, R.I., SANTOYO, M.C., MADRIGAL, J.B., ÁLVAREZ, B.E. and AVILA, M.G. In vitro evaluation of prebiotic activity, pathogen inhibition and enzymatic metabolism of intestinal bacteria in the presence of fructans extracted from agave: A comparison based on polymerization degree. LWT, 92, 2018, p. 380-387. doi:https://doi. org/10.1016/j.Iwt.2018.02.051

[34] SANTARMAKI, V., KOURKOUTAS, Y., ZOUMPOPOULOU, G., MAVROGONATOU, E., KIOURTZIDIS, M., CHORIANOPOULOS, N. and YPSILANTIS, P. Survival, intestinal mucosa adhesion, and immunomodulatory potential of Lactobacillus plantarum strains. Current microbiology, 74(9), 2017, p. 10611067. doi: $10.1007 / \mathrm{s} 00284-017-1285-z$

[35] SONG, Y.G. and LEE, S.H. Inhibitory effects of Lactobacillus rhamnosus and Lactobacillus casei on Candida biofilm of denture surface. Archives of oral biology, 76, 2017, p. 1-6. doi: 10.1016/j. archoralbio.2016.12.014.
[36] MOKOENA, M.P. Lactic acid bacteria and their bacteriocins: Classification, biosynthesis and applications against uropathogens: A mini-review. Molecules, 22(8), 2017, p. 1255. doi: 10.3390/ molecules22081255

[37] ÖZOGUL, F. and HAMED, I. The importance of lactic acid bacteria for the prevention of bacterial growth and their biogenic amines formation: $A$ review. Critical reviews in food science and nutrition, 58(10), 2018, p. 1660-1670. doi:https:// doi.org/10.1080/10408398.2016.1277972

[38] BUCKOVÁ, B., HURNÍKOVÁ, Z., LAUKOVÁ, A., REVAJOVÁ, V. and DVOROŽŇÁKOVÁ, E. The anti-parasitic effect of probiotic bacteria via limiting the fecundity of Trichinella spiralis female adults. Helminthologia, 55(2), 2018, p. 102-111. doi: 10.2478/helm-2018-0010

[39] BUSTIOS, C., VERGARA, V. y CHAUCA, L. Suplementación de $\beta$-caroteno en dietas balanceadas con exclusión de forraje en cuyes (Cavia porcellus) reproductoras hembras. Revista de Investigaciones Veterinarias del Perú, 29(3), 2018, p. 756-76 doi:http://dx.doi.org/10.15381/rivep.v29i3.147829 